\title{
Barriers and Enabling Factors Associated with the Implementation of Household Solar Water Disinfection: A Qualitative Study in Northwest Ethiopia
}

\author{
Bikes Destaw Bitew, ${ }^{1 \star}$ Yigzaw Kebede Gete, ${ }^{2}$ Gashaw Andargie Biks, ${ }^{3}$ and Takele Tadesse Adafrie ${ }^{4}$ \\ ${ }^{1}$ Department of Environmental and Occupational Health and Safety, Institute of Public Health, College of Medicine and Health Sciences, University \\ of Gondar, Gondar, Ethiopia; ${ }^{2}$ Department of Epidemiology and Biostatistics, Institute of Public Health, College of Medicine and Health Sciences, \\ University of Gondar, Gondar, Ethiopia; ${ }^{3}$ Department of Health Service Management and Health Economics, Institute of Public Health, College of \\ Medicine and Health Sciences, University of Gondar, Gondar, Ethiopia; ${ }^{4}$ Department of Epidemiology and Biostatistics, School of Public Health, \\ College of Health Sciences and Medicine Referral Hospital, Wolaita Sodo University, Wolaita, Ethiopia
}

\begin{abstract}
Household water treatment including solar disinfection (SODIS) is recognized worldwide as an important intervention for prevention and control of diarrheal and other waterborne diseases. However, in Ethiopia's countryside, SODIS is not being practiced. Therefore, the objective of this qualitative study conducted in villages of Dabat district in northwest Ethiopia was to explore barriers to and enabling factors for consistent and wider implementation of SODIS. This phenomenological study design included four focus group discussions with 25 parents of children younger than 5 years and interviews with four key informants to elicit their experiences and opinions. ATLAS.ti 8.0 software $(\mathrm{GmbH}$, Berlin, Germany) was used for data organization, and the content was analyzed thematically. Enabling factors were categorized into four themes, such as supportive values for SODIS (positive attitude, advantage of SODIS, and cultural acceptance of SODIS), consistent use of SODIS (community's interest, health education, availability of bright sunlight, and simplicity of the method), participation of family and community in daily implementation of the SODIS process (controlling theft of bottles and recognizing the importance of SODIS technology), and willingness to pay for new polyethylene terephthalate (PET) bottles. On the other hand, barriers were grouped into three themes such as sociocultural (poor knowledge, hesitation to leave SODIS bottles unguarded outdoor, less attention, and unplanned social events), environmental (cloud, shadow over SODIS bottles, turbidity and leeches in source water, and geographical settings), and behavioral (mishandling of SODIS bottles and drinking water). The analysis of the data revealed that all the participants had positive attitude toward the implementation of SODIS, and it was culturally accepted. They identified the barriers to and enabling factors for the implementation of SODIS. Promoting enabling factors and mitigating barriers are substantially important for consistent implementation of SODIS as a long-term interventional measure widely in rural Ethiopia for the achievement of the goal of safe drinking water for all.
\end{abstract}

\section{INTRODUCTION}

A major challenge for developing countries is the lack of continuous access to safe drinking water. Eight of 10 rural people consume water from unimproved sources. ${ }^{1}$ According to the WHO estimates, 2.1 billion people lacked safe drinking water services. About 159 million were collecting drinking water directly from surface water sources. In sub-Saharan Africa, nearly $58 \%$ of people did not have access to safe drinking water. ${ }^{2}$ Safe water means clean water that is free from pathogenic microorganisms, suspended matter, and turbidity, and suitable for consumption. ${ }^{3}$

Sustainable approaches to safe water management involve wider community recognition of policy, practice, and technology modifications that, in turn, require a community engagement. The first critical step in building a committed community is to identify community-based indigenous knowledge and experience of safe water management enablers and barriers. ${ }^{4}$ Health authorities accept a water treatment intervention worldwide, and ensuring water quality intervention was a pillar of primary prevention and control of diarrheal and other waterborne diseases., ${ }^{5,6}$

Ethiopia planned to raise the safe water supply coverage to the population up to $83 \%$ by the year 2020 from the $58 \%$ coverage in $2015^{7}$ despite the prohibitive costs of capital and maintenance of conventional large-scale water treatment

\footnotetext{
* Address correspondence to Bikes Destaw Bitew, Institute of Public Health, College of Medicine and Health Sciences, University of Gondar, North Gondar, P.O. Box 196, Gondar, Ethiopia. E-mail: bikesdestaw2004@gmail.com
}

plants. ${ }^{8}$ Consistent implementation of household water treatments (HWTs) such as solar disinfection (SODIS), water boiling, chlorination, filtration, and safe water storage practices could be alternative interventions to manage water safety at home $e^{9}$ and could be contributed to the achievement of the Ethiopia's second Gross Transformation Plan (GTP-II) targets as well as the sustainable development goal-6, "achieve universal and equitable access to safe water and affordable drinking water for all in 2030."

Solar disinfection is a user-friendly method of HWT to have safe drinking water. The technique only needs transparent 2-Lor lesser volume PET bottles filled with water in which the combined effects of solar radiation and heat-kill most of the pathogenic microbial contaminants. ${ }^{10}$ However, different barrier and enabling factors may variously influence the feasibility of consistent implementation of SODIS in the villages of Ethiopia. ${ }^{11,12}$ Of all the factors, willingness of rural households to pay for safe water supply is a crucial factor that affects their access to safe drinking water. ${ }^{13}$

Few studies ${ }^{14,15}$ from Ethiopia reported the importance and effectiveness of SODIS at rural households and also found that this simple HWT technique was not being practiced in Ethiopia. However, none of those studies determined enablers and barriers to wider acceptance and implementation of SODIS at the household level by the rural communities. ${ }^{16}$ Therefore, the present qualitative study was conducted in Dabat district of northwest Ethiopia to understand parental perceptions about the importance of clean water and HWT practices and determine the barrier and enabling factors for acceptance and consistent implementation of SODIS at the rural households as a long-term interventional measure in Ethiopia. 


\section{METHODS}

Study design and period. A phenomenological design was used to explore participant experiences about barriers and enabling factors to implement SODIS by using focus group discussions (FGDs) and key informant interviews (KIls), technique used for data acquisition in Dabat district, northwest Ethiopia, in October 2016.

Study settings and population. The study was conducted in Dabat district located in Amhara administrative regional state, northwest Ethiopia (Figure 1). The University of Gondar (UoG) selected Dabat district to serve as a site for the Health and Demographic Surveillance System (HDSS) site since 1996. ${ }^{17}$ The study site covered 13 randomly selected kebeles, which include four urban and nine rural kebeles (lowest local administration units in Ethiopia). The study area is predominantly rural, and the residents largely depend on the mix of livestock and subsistence farming. The total population of the HDSS site was estimated at about 70,611 by $2012 / 13$ projection. Of the total population in the study area, nearly $76 \%$ were from rural areas. ${ }^{18}$ Rural households collect drinking water from wells, springs, and/or rivers, and 20 -L jerricans were used for water storage at home. ${ }^{16}$

Sample size and sampling techniques. A purposive sampling technique was used to select 25 individuals (three groups of women and one group of men) as study participants for FGDs and four individuals for KIls based on their experiences of SODIS water treatment, knowledge of safe water handling, local representativeness, and ability to express their thoughts. Of the 25 participants in the FGDs, 18 were chosen from 12 SODIS intervention villages (villages wherein SODIS was implemented by the people as a part of a trial study that was conducted earlier) and seven from three control villages (villages wherein the people never implemented SODIS). Each focus group consisted of six participants except one women's group that included seven. The FGD participants were parents of children younger than 5 years. Two focus groups comprised only mothers and one group with only fathers were from intervention villages, and one group with only mothers were from nonintervention villages. Of the four participants in the Klls, two were health extension workers (HEWs), one from the coordinating office of the Woreda Health Extension Program, and one from the Dabat woreda (district) Water Development Office.

Data collection. Data collection was facilitated by the principal investigator who organized the overall field activities. Two experienced instructors at the UoG, one with environmental health and the other with behavioral science background were also recruited to execute the group discussions and interviews. In addition, two reporters engaged, one from UoG and the other from Dabat HDSS site for writing field notes and audio recording the discussions and interviews.

The data collection tools were semi-structured interview with probing questions for KIls and semi-structured FGD guide, both prepared in local language (Amharic). The interviews and FGD guide included open-ended questions which explored various aspects, such as the concept of clean water, need of HWT for those who collected water from unimproved water sources, source of water contamination, barriers, and enabling factors related to SODIS implementation. Interviews and FGDs were conducted after relevant permissions and consents were obtained from participants. All the discussions and interviews were recorded in audio tapes as well as field notebooks simultaneously. The audio recordings were carefully and completely transcribed verbatim. Orientation was given to interviewers/data collectors about ethics of interview and ways of probing for required details and efficient management of the discussions. Before the commencement of the actual data collection, a pretest was administered to ensure the clarity of questions, the understandability of terminologies, to identify questions that may reflect any hidden bias, to check if leading questions are included, consistency of terms, and to check logical order of relevant open-ended questions. All the

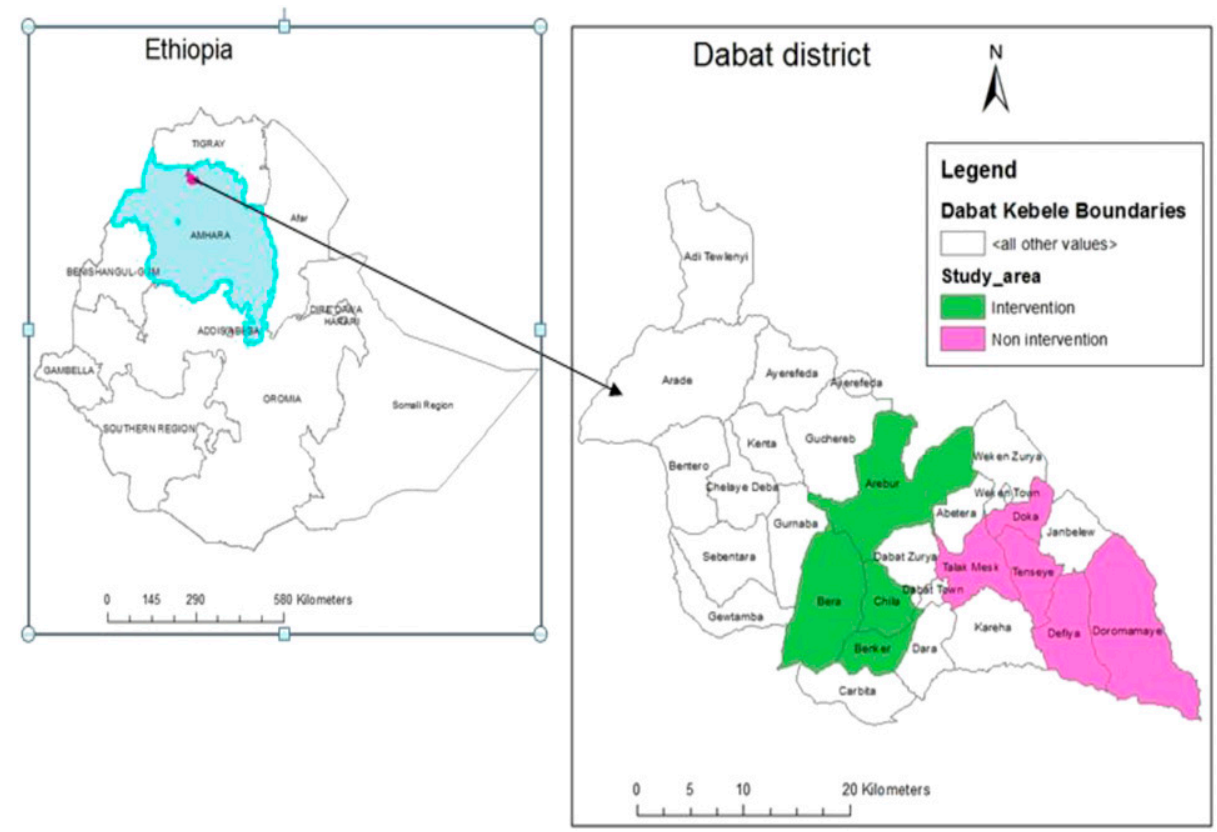

FIGURE 1. Map of Ethiopia, Amhara regional administrative state, Dabat district, and Dabat Health and Demographic Surveillance System site, 2016. This figure appears in color at www.ajtmh.org. 
discussants were allowed to express their ideas until the saturation point was reached. Probing questions were designed for assisting the moderators in the quest for data saturation after comprehensive understanding of the raised issues. The durations of the meetings have taken a minimum of 70 minutes for KIls and a maximum of 165 minutes for FGDs.

Data management and analysis. Data were transcribed verbatim in Amharic and translated from Amharic into English. The audio-recorded and the fieldnote data were checked for accuracy and completeness. The transcribed data were read more than three times to conceptualize the meaning of contexts. Word transcript documents were directly imported and analyzed thematically by using ATLAS.ti-8.0 software (GmbH, Berlin, Germany). At first, the transcripts were carefully read and coded line by line. Inconsistencies of data were clarified through rechecking field records and reducing nonstandard data. Even during data display and reduction, the investigators reviewed earlier steps to refine codes, reread the texts, and revised some aspects of the analysis. The transcription and data coding were carried out by the principal investigator.

For the consistency of the recorded data, transcription was rechecked by four experienced researchers to confirm the correctness of the translation of audio records.

Ethical consideration. Ethical clearance was obtained from the Institutional Review Board of the UoG (Ref. No: R/C/S/N/P/ 05/541/2015). An informed written consent with the signature or thumbprint was secured from every discussant after informing them about the relevance and importance of their participation. Permission for audio recording was also obtained from all the participants, and anonymity was guaranteed.

\section{RESULTS}

Characteristics of participants. The FGDs and KIls involved a total of 29 participants. Most of the participants $(86.2 \%)$ were married, and nearly two-thirds $(65.5 \%)$ of them were housewives (Table 1). The mean $( \pm S D)$ and median ages of the participants were $31.9( \pm 8.5)$ and 30 years, respectively, and the age ranged from 18 to 58 years. The average ( \pm SD) time for each FGD and KII was $150( \pm 11)$ and $75( \pm 7)$ minutes, respectively.

TABLE 1

Sociodemographic characteristics of focus group discussion and key informant interview participants in Dabat district, northwest Ethiopia, October 2016

\begin{tabular}{llrr}
\hline Characteristic & \multicolumn{1}{c}{ Categories } & Number & $\%$ \\
\hline Gender & Male & 8 & 27.6 \\
& Female & 21 & 72.4 \\
Occupation & Housewife & 19 & 65.5 \\
& Farmer & 6 & 20.7 \\
& Health extension worker & 2 & 6.9 \\
& Health professional & 1 & 3.4 \\
& Water development worker & 1 & 3.4 \\
Marital status & Married & 25 & 86.2 \\
& Single & 3 & 10.3 \\
Education & Widowed & 1 & 3.4 \\
& Illiterate & 10 & 34.5 \\
& Grades 2-10 & 15 & 51.8 \\
& Diploma & 3 & 10.3 \\
& Degree & 1 & 3.4 \\
\hline
\end{tabular}

Understanding of participants about clean drinking water. To understand the overall awareness of the participants about the concept of clean drinking water, the data/ responses are categorized into three subthemes:

\section{Knowledge about clean water}

More than three-fifths (62\%) of the participants correctly described the meaning of clean water. A representative statement of FGD participants $(P)$ from the SODIS intervention villages was stated that "clean water is the drinking water that did not cause diarrhea and infestation of intestinal parasites" (FGD1P3).

\section{Knowledge about water treatment at home}

The study participants from both SODIS intervention and control villages knew the HWT methods-boiling of water and filtration of water through locally available materials such as cloth and sieves made of sack fibers, a piece of old mosquito net, and dried gourd fiber. Nearly two-thirds of the participants (64\%) from the intervention villages gained the knowledge about the SODIS method through the implementation of SODIS trials. One of the FGD participants said that "Previously, boiling of water was a common practice at home... Now, we used SODIS method combined with cloth filtration....." (a 28-yearold woman from the intervention village, FGD1P2).

\section{Knowledge about sources of water contamination}

A couple of the following representative descriptions revealed the knowledge of the participants about the sources of water contamination at the water source and at home:

Contact of water with cattle, donkeys, and horses as they used the same water sources as we used; washing and bathing of shepherds and water collectors at upstream locations. (A 36-year-old woman from the intervention village, FGD1P4)

... at home, dirty water containers, like Jerry cans, widenecked pots, barrels, cups, children, pets, and chickens moving on dirty floor contaminate water. (A 28-year-old woman from the intervention village, FGD1P6).

Enabling factors to implement SODIS. For analysis purposes, the enabling factors are organized into the following four subthemes.

\section{Supportive values for SODIS use}

Some of the common supportive values associated with the implementation of SODIS were expressed by the participants. They were, in descending order, positive attitude toward SODIS, advantages of SODIS (e.g., no need of spending fuel for boiling of water and water boilingassociated accidents do not occur), interest and demand of children for SODIS-treated water, access to corrugated iron sheets for laying SODIS bottles for exposure to sunlight, presence of school-going children in households, availability of a sufficient number of PET bottles, and acceptance of SODIS culturally. One of the supportive statements of the FGD participants was 
Using SODIS without forgetting even for a day is not an issue because water is life ... and our children urged us to offer them SODIS treated water bottles... They are very delighted to drink water from SODIS bottles... Their enthusiasm inspired us to implement the SODIS method continuously. (A27-year-old woman from the intervention village, FGD2P6).

\section{Consistent use of SODIS}

Study participants suggested possible conditions for consistent use of SODIS such as motivation of the community, health education, accessibility of PET bottles in terms of availability for all households, in local markets, low price, and durability, availability of bright sunlight, integration of SODIS implementation in health extension package, simplicity and user-friendliness of SODIS for rural communities, and improvement in health. One of the illustrative statements of the participants from intervention villages was

Neighboring households expressed their interest for implementing SODIS.... My neighbor pregnant woman asked me to give her the SODIS treated water and I always gave her a bottle of water. (An FGD1 female participant).

One of the HEWs also explained during the KII the feasibility of consistent implementation of the SODIS at households as

SODIS is less expensive and affordable across the rural communities. Households in the intervention village gained better understanding about SODIS through practice. I noted that the households did not support boiling water because of the expenditure on fuel, fear of boiling-related accidents at home, and health problems due to indoor air pollution. The community now has gotten interest in using SODIS to provide their children with clean water. Community mobilization can be a priority action for popularizing consistent use of the SODIS. (A27year-old HEW from KII)

\section{Family and community participation}

The FGD participants identified the roles of family members in SODIS-related activities at their homes, such as washing SODIS bottles, exposing of SODIS bottles to sunlight daily, monitoring the SODIS process, and ensuring clean water accessibility to their children. The discussants also pointed out the tasks at the community level, such as the recognition of SODIS technology as an HWT method, distribution of SODIS bottles to households and encouraging them to implement the method, monitoring and evaluating the HWT, conducting water source sanitation, providing health education for community at large and for children at school, and controlling theft of SODIS bottles. An illustration was

Family members' participation is very important for the proper implementation of the SODIS method as it can assist households in monitoring the SODIS process, washing the bottles, exposing them to sunlight, and encouraging children to drink SODIS treated water, whereas, community participation can be helpful in terms of protecting and cleaning common water sources that would provide suitable raw water for SODIS treatment. (A 28-year-old woman from the intervention village, FGD1P6)

\section{Willingness to pay for SODIS bottles}

Users' willingness to pay for SODIS bottles is a vital enabler for sustainable implementation of SODIS at household levels. Participants expressed that the rural people could afford to buy SODIS bottles if available at the local level. The representative comments and observations emerged in the FGDs and Klls were

Currently, government has provided us SODIS bottles free of cost, but subsequently we may have to purchase. As we understand the advantages of SODIS, I can buy a $2 \mathrm{~L}$ bottle at a cost from Ethiopian Birr (ETB) 6.00 (US\$0.273) to ETB 10.00 (US\$0.455) for preventing our family health problems especially of children due to unsafe water consumption. (A 36-year-old woman from intervention village, FGD1P4)

On probing what could be the purchasing ability and willingness of the community if an industry-market linkage would be established to bring transparent PET bottles into local communities, the response was

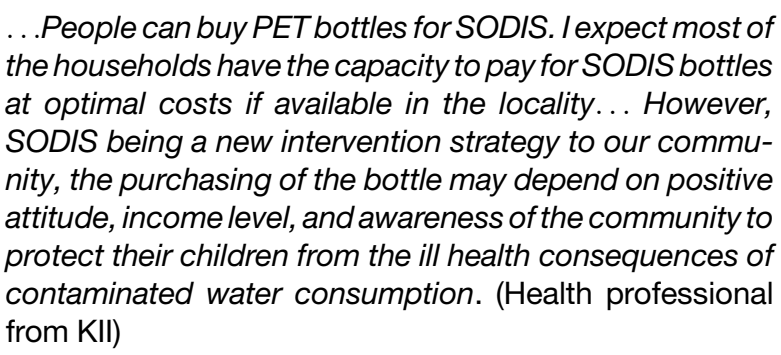

Barriers to SODIS implementation. The main theme for the assessment of barriers to implement SODIS at the rural household level was subthemed as sociocultural, environmental, and behavioral barriers that are described in the following sections.

\section{Sociocultural barriers}

The sociocultural barriers identified by the participants were poor knowledge of community, hesitation to put SODIS bottles outdoor for exposure to sunlight because of various apprehensions, less attention to HWT, and unplanned social events. The illustrations are presented in the following text.

\section{a. Poor knowledge of community}

Poor knowledge of people is reflected in the following statements of the respondents:

The main problems in offering clean water to children are poor knowledge that leads to the use of unprotected water sources, less commitment to receive health education about safe water, low practice of HWT, and unfavorable attitude. We [parents] have an old saying "Wuha Biruk, Wuha Kidus" [i.e., water is blessing; water is holy] 
that reflects wrong a perception- "water does not have any negative effect on health even if one drinks it without treatment". This old saying and perception is not correct. However, we are still following it due to lack of basic knowledge. (A 28-year-old woman from intervention village, FGD1P6)

b. Hesitation to keep SODIS bottles outdoors for solar exposure

The participants widely discussed community's traditional worries about exposing SODIS bottles outside the house without vigilance by family members. Their reflections were

I have different reasons for not exposing SODIS bottles without a guard. Some irresponsible individuals may add poisonous substances, like rat poison into bottles; somebody may take the bottles away to use them for other purposes; and, I don't rely on child guards of SODIS bottles as they are not responsible. (A 35-year-old woman from the intervention village, FGD1P5)

In response to the question why people presume somebody would add poisonous substances into water bottles, participants said, "Our resolve to be highly careful is due to our belief in the saying 'man does not err and iron does not rust are inconceivable'. Some irresponsible individuals who are disappointed with their neighbors may revenge by adding poisonous substances into SODIS bottles" (FGD1P4).

c. Less attention to HWT

People do not pay much attention to treating water at home because of personal weakness, negligence, or laziness as may be seen in the following statement:

Household water treatment is less likely to be practiced due to lack of awareness, personal weakness, and inadequate health education ... Otherwise HWT is a simple job. Weakness means, parents are less motivated due to their belief that water treatment will cause physical fatigue; they lack passion for HWT work and thus pay less attention to the care of their children. (A 45-year-old man from intervention village, FGD3P3)

A key informant from the woreda health office pointed out the KII lack of attention toward HWT and lack of integrated actions for the improvement of safe water access at household levels due to poor integration between the health and water development sectors.

Poorintegration between the woreda health office and the water development office has been a serious problem to implement HWT in the community. For instance, the health office is responsible to educate the community and work on water, hygiene, and sanitation activities, including diarrhea prevention. Budget for water, sanitation, and hygiene (WASH) activities was allocated to the woreda water development office. But, the office did not engage in the household water safety plans. Thus, strong inter-sectoral collaboration activities would have been a priority to provide sustainable safe water supply to households. (Health professional from KII)

\section{d. Unplanned social function}

Urgent travelling to other areas for social purposes, domestic workload of household members, and sickness of responsible persons who implement SODIS at home were the exigencies hindering the regular process of SODIS implementation daily at household levels. A representative expression of the participants is given in the following paragraph:

Two main reasons for interruption of SODIS are domestic workload and attending funeral ceremonies and mourning's. Most of the time, my husband helps by exposing SODIS bottles and monitoring the daily activities whenever I am overloaded and not present at home. . .(A 28year-old woman from the intervention village, FGD1P4)

\section{Environmental barriers to implement SODIS}

Participants identified environmental barriers to consistent practice of SODIS at household levels, such as cloud cover that obstructs sunlight; shadows over the SODIS bottles; small size of SODIS bottles; unprotected, turbid, and leech-infested water sources; and inaccessible geographical settings to reach water sources as evident from the following illustrations:

The common problem I have observed to practice SODIS continuously was cloud cover that dims the sunlight. (A woman from intervention village, FGD2P6)

Some of the observed problems to implement SODIS at households include the use of SODIS bottles for other purposes, small size of bottles, and the presence of cloud covers, especially during rainy season. (Water development office employee during KII)

Participants from the control villages (i.e., nonintervention village) emphasized a local problem of the presence of leeches in their common well, spring, and river waters. One of their statements was "In our village, presence of leeches in the water sources is a great problem. In fact, leeches mostly pose problems to animals that drink water from these open sources" (a 32year-old woman from nonintervention village, FGD4P5).

The leech in water is likely to be swallowed unless it is filtered out or destroyed by boiling the water. Water users may not apply the SODIS method unless the leech is removed from the water.

\section{Behavioral barriers to SODIS implementation}

Study participants explained behavioral factors such as children playing with SODIS bottles and spoiling the treated water in it, use of SODIS bottles for other purposes, using dirty cups for drinking water, and unhygienic practices at home as barriers to practice SODIS at households. The illustrations are as follows:

Some of the children often add dirts into SODIS bottles while playing with them, drop the bottles into stove fires, or throw away after drinking the water, particularly when the caps of the bottles are lost. Of course, it is difficult to control the behavior of some of the children. (A 30-yearold man from intervention village, FGD3P1) 


\section{DISCUSSION}

The qualitative design of this research allowed the researchers to gain insights from the participants about the clean and safe drinking water and barriers to and enabling factors for the implementation of SODIS in rural villages in northwest Ethiopia. More than three-fifths of the participants $(62 \%)$ had a good understanding of the use of clean water. Participants from the SODIS intervention villages knew about boiling and filtration as HWT methods and gained working knowledge about SODIS as a result of intervention trials conducted earlier. ${ }^{15}$ They realized SODIS as an easy and safer technique of HWT than boiling of water. Participants were also conscious of three major causes of inferior drinking water quality, poor design of water storage containers, unhygienic water handling practices, and animal contact with water sources. The participants from the nonintervention villages were not aware of SODIS as a HWT, although they knew boiling and filtering of water.

Knowledge of participants about clean water, water treatment, and sources of water contamination. Comprehensive understanding and knowledge of participants on clean water, water treatment at home, sources of water contamination, and associated problems linked to the management of potential water quality risks are essential for efficient management of drinking water systems. ${ }^{19}$

Discussions with participants in the focus groups and interviews of key informants assist the water consumers to comprehend and contribute to the choices on improving the implementation of alternative HWT methods. However, there was no similar knowledge level among all participants about the meaning of clean water and effective water treatment methods at the household level.

Nearly two-thirds of the participants in this study (63.6\%) recognized the concept of clean water in terms of SODIS or chlorine treatment, and water which is free from the causes of diarrhea and intestinal parasite problems. Some participants, however, wrongly considered that colorless and turbid-free source water that was apparently "sparkling water" as "clean water" and it could be used for drinking purposes without any risk of significant adverse health effects. Rojas and Megerle in their study in rural Medellin, Colombia, reported that more than three-fourths (83\%) of their study participants having such a wrong perception drink the apparently transparent water without any treatment. ${ }^{20}$ Similar findings from a study in the northwest province of South Africa ${ }^{21}$ also revealed that most community inhabitants understood the quality of drinking water as associated to the apparent clarity and brightness of the water, as well as other organoleptic characteristics such as odor and taste. Such a perception leads to raw water intake being accepted irrespective of the understanding of the presence of waterborne pathogens in it. However, a Peruvian Amazon community thought that turbidity was an indicator of water quality associated with health risks. ${ }^{22}$

Indigenous knowledge of rural communities as can be understood from the study participants is very important to understand HWT methods and thereby to ensure clean water supply. Although participants expressed their thoughts irrespective of effective water treatment status, the destruction of pathogenic organisms by all types of HWT methods is not equally efficient. "Adequate" methods of HWT such as boiling, chlorination, and SODIS help to completely remove pathogens, whereas "inadequate methods" such as homemade filtration, sedimentation, and water storage cannot completely remove pathogens. $^{23}$

Sixty-four percent of the participants in this study mainly acknowledged SODIS as a method of HWT. Our previous rural community intervention trial of SODIS helped the public gain such a new awareness and knowledge. This finding is consistent with that of a Bolivian study as reported by Christen and others ${ }^{24}$ that SODIS-related commitments were associated with gaining new knowledge about drinking water treatment. Boiling was the most common effective HWT method in rural southern India, similar to our finding, but "warming water" was erroneously perceived as equal to boiling water for children's consumption. ${ }^{18}$ Some of our participants shared their experiences including the perceptions of rural community about alternative use of HWTs, such as water storage, decanting after sedimentation, and homemade filtration. Findings related to filtration are consistent with findings in rural southern India, that is, water filtration with cloth or sieve that was ineffective as only dirt but not pathogens could be filtered out. $^{18,25}$ In Nepal, ${ }^{26}$ households used cloth filters to remove visible cloudiness from water but did not relate it to the prevention of disease. Water storage has been regarded by six African communities in the northwest province of South Africa as a widely recognized method of keeping water quality. ${ }^{21}$

Understanding the contamination of the water source is notable because it facilitates the selection of good quality water sources for drinking water supply and offers a basis for establishing treatment requirements within the WHO standard limits. ${ }^{19}$ This study attempted to explore participants' knowledge of water quality from protected sources. For two primary reasons, three-fifths of participants $(60 \%)$ proposed that drinking water from protected sources should be treated at the household level. First, like unprotected sources of water, protected sources are also liable to infiltrate external contaminants from multiple sources, for example, through cracked structures and defective joints. Second, drinking water from protected water sources may become contaminated at home because of poor handling methods. This observation is consistent with those from other studies in Cambodia $^{27}$ and Bolivia ${ }^{28}$ that stated that improved on-site water might be subjected to further contamination once stored at the household level.

Enabling factors to implement SODIS. To implement SODIS at the household level, study participants mentioned possible combined enabling factors. Participants from the SODIS intervention villages agreed that SODIS was a feasible HWT technique that was culturally acceptable and the SODIS treated water was palatable. This observation is compatible with the findings of a prior study by McGuigan and others ${ }^{29}$ who reported that SODIS was an efficient and culturally acceptable method for Cambodia's rural communities. In addition, a study in $\mathrm{Nepal}^{26}$ showed that most participants valued SODIS as an acceptable method as the treated water was palatable and more suitable for better health gain. Participants in the present study showed that a favorable attitude was useful for the sustained use among rural communities of SODIS intervention. This is in line with the result of a study in rural Peru, ${ }^{30}$ which found that nearly $42 \%$ of households positively viewed SODIS as a promising new intervention approach and used the method continually since the intervention report was released 7 years ago. 
Before the widespread dissemination of SODIS to improve community-level drinking water quality, investigators explored community experiences of consistent use of SODIS through FGD and KII techniques.

A study by Kraemer and Mosler in Zimbabwe ${ }^{11}$ supports the findings of the current study. The study noted that the community's acceptance of SODIS could be determined in terms of such persuasive factors as community interest, knowledge, attitude, involvement, and values, in relation to the accessibility of bright sunlight and bottles. Moreover, Rose et al. ${ }^{12}$ determined the ease of use, economic consequences, and mechanisms of action as stated by FGD participants as factors related to the acceptability of SODIS. The present findings are also consistent with that of a review document submitted at an international conference held in Ethiopia in $2009,{ }^{31}$ which addressed factors allowing acceptance and dissemination of the SODIS method. The debate disclosed that SODIS had the ability to gain the acceptance of many water consumers globally who would decide to use the method because of its benefits in terms of effectiveness, low price, broad accessibility of sunlight, and affordability of bottles and other supporting materials. In addition, repeated education/training and promotional actions through large-scale WASH programs can also be useful enablers for the communities to follow the SODIS method. The participants in this study proposed that SODIS could be maintained not only by the simple accessibility of PET bottles but also by its inclusion with existing packages for health extensions. This finding is supported by the work of Meierhofer and Landolt, ${ }^{32}$ which reported local accessibility of bottles, extensive training, and SODIS inclusion with regular programs and local institutions (e.g., schools, health centers, health posts, local and top-level government structures) could add to the beneficial impact of sustained use of SODIS at the household level. The particular duties involved in the continuous application of SODIS in a household that family members could share were identified as monitoring the implementation of the SODIS method and encouraging children to drink SODIS-treated water. These findings are consistent with those reviewed by McGuigan and others. $^{29}$ The findings of Rainey and Harding in Nepal ${ }^{26}$ indicated that children's involvement in filling and exposing SODIS bottles in particular would relieve mothers of this liability and facilitate the SODIS process at home. The willingness of the SODIS user to bear the price of the bottles is a key factor in the household level implementation of the SODIS method. Both the participants of the FGD and KII discussed and highlighted the potential consequences of the community level related to purchasing ability and people's intention to pay for PET bottles if made accessible locally. All participants of the FGD expressed their willingness to buy the bottles and confirmed the positive attitude of their community. However, all of them agreed that enhancing awareness among rural communities should be done before bottles are distributed through health education and promotion programs. This is in line with Nepal's report ${ }^{26}$ that revealed that cues to action serve as a reminder to stimulate the behavior of a person. Some suggestions have been forwarded by participants of the present study, such as designing a reasonable approach to distribute bottles, evaluating SODIS in terms of family health benefits, and setting affordable bottle rates. Some participants proposed ETB 2.00-3.00 (US\$0.091-0.136), whereas others proposed that ETB 6.00-10.00 (US\$0.273-0.455) be affordable by most households for a 2-L transparent PET bottle. This is consistent with the findings in Nepal ${ }^{26}$ that purchasing the bottles was not a problem to implementing SODIS if the bottles were made available at the community level.

Barriers to implement SODIS. To understand the challenges of successfully implementing SODIS at the household level, a thorough exploration of participants' varying views on barriers that hinder the implementation of SODIS water treatment is essential. Participants discussed the barriers grouped as sociocultural, environmental, and behavioral.

Sociocultural barriers. The most focused part of the factors in this study was barriers related to sociocultural components. Barriers to community acceptance and sustained use of SODIS would discourage them from benefiting from SODIS interventions, thus putting children at a high risk of waterborne diseases. ${ }^{18,33}$ The participants often described various sociocultural barriers that would hinder the adequate SODIS treatment of water at home. The parents' existing traditional beliefs—such as "water is a blessing; water is holy," which implies that drinking water does not cause health problems, regardless of its cleanliness-would lead to the incorrect management of drinking water safety at home. Sometimes households could not allow SODIS bottles to be subjected to full-time sunlight without continuous vigilance because of some prejudiced community concerns, such as fear of intentional water poisoning by adversaries. Such prejudiced fears are part of Ethiopia's study area's existing cultural concepts of rural communities. For instance, many individuals think that revenge would be taken on their neighbors or any other individual with whom they had a quarrel or altercation. Although, in fact, they have not witnessed any such poisoning cases, they have not kept SODIS bottles out in sunlight unless they are able to watch them. There have also been reports of such cultural tendencies from another African country, Zimbabwe. ${ }^{34}$

The participants of the FGD frequently described widespread barriers to the uninterrupted implementation of SODIS related to parents' unplanned social functions. Such practical barriers were women's workload, both domestic and agricultural, although men practically supported the HWT, and parents going to other areas to attend social meetings, such as funeral ceremonies, or grain milling, or markets. These findings are in line with that of a comparable work in Bangladesh $^{35}$ that revealed the reasons for SODIS irregularity as a reluctance to treat water, misunderstanding that it is a hard task to treat a large quantity of water, and finding it difficult to spare time for the treatment process. A study by Rainey and Harding in $\mathrm{Nepal}^{26}$ pointed out that water treatment was a minor aspect of women's concerns and that women's domestic and farming workload was the most common barrier. ${ }^{36}$

In this study, the participants revealed that because of personal weakness of family members, some parents paid less attention to HWT. These findings are also supported by William et al.' ${ }^{37}$ qualitative study findings in Haiti, which indicated that because of negligence, laziness, or belief that water treatment was not essential, individuals did not treat their water at home. Solar disinfection was considered economic despite the fact that bottles were exposed to theft, according to Rose et al.'s ${ }^{12}$ findings from southern India, and poorer households in Bolivia have not adopted SODIS. $^{24}$ 
Environmental barriers. Cloud coverings, shadows, unprotected turbid water sources, the presence of leeches in water sources, and geographical locations were commonly considered environmental barriers to household-level implementation of SODIS.

The most typical environmental barrier to successful treatment of water with SODIS was the cloud cover problem during the rainy season. The participants proposed that water boiling be used as temporary alternatives to solve this problem until the cloud cover would disperse and sunlight would become brighter. This finding is consistent with the work of Borde and others ${ }^{25}$ which was not recommended during heavy rainfall and revealed that it needed 2 days of exposure in cloudy conditions to adequately disinfect water. A more prevalent problem in rural areas is the shadow of trees and buildings falling on exposed bottles. However, when the shadow reaches the exposed bottles, family members can move the bottles to non-shadow places. If the bottles remained in shadows, the pathogenic organisms would not be adequately destroyed because the bottle surfaces cannot be reached by the sunrays, and the shadows would lower the bottle water temperature. $^{8}$

Source water quality is one of SODIS water treatment's significant limiting factors for effectiveness. High turbidity was observed to reduce the effectiveness of SODIS by reducing the effect of sunlight penetration across water depth, thus preventing microbes from inactivation. ${ }^{14,36}$ In this study, the participants suggested early morning collection of water from the sources (i.e., "before birds singing" in local speech) because contact of animals with water that disturbs and contaminates the water is less likely and letting the collected water for simple sedimentation at home before filling SODIS bottles to minimize the effect of turbidity.

Rough terrains and remote water source locations are geographic barriers to SODIS implementation. Because of the lack of water sources close to the community, individuals often have to walk long distances to obtain water. In this study, participants shared their experiences of gathering water from remote areas after walking through rough geographical environments due to dry season drying nearby common water sources. These conditions have forced households to save and keep water for longer periods of time, and SODIS contribution is limited. ${ }^{24}$

Behavioral barriers. Compliance with SODIS implies behavioral change as consumers have to organize bottles, wash, fill them with water, put them in the sunlight, and retrieve them after exposure is adequate. Moreover, the water cup used for drinking must be clean; otherwise, there is a high risk of recontamination. ${ }^{28}$ Participants discussed and highlighted the behavioral factors that hamper SODIS's household level of safe water availability. Such factors included children playing with SODIS bottles like toys, deforming bottles by exposing them to fire or damaging them by any other means, making them nonfunctional, scratching bottle surfaces, misplacing bottle caps, and using SODIS bottles for other purposes, such as storing edible oil, spoiling children's SODIS-treated water, adding dirt in bottles, and drinking water with dirty cups. Other studies on behavioral factors in SODIS use, ${ }^{26,29}$ however, did not recognize children's behavior as barriers to implement SODIS at home, although some children are too subtle to manage.

\section{LIMITATIONS}

Because of the inherent limitations of the qualitative method, subjectivity could not be completely excluded. ${ }^{38}$ Selfreported behaviors may be subject to bias in terms of social desirability, and confirmation bias is also a potential restriction of FGD despite the reality that participants have been encouraged to express alternative points of view through probing questions. It may not be representative of the general population to use purposive sampling with a small sample size. Only mothers and fathers of children younger than 5 years were invited to participate which could lead to a selection bias. Participants may not have properly internalized barriers and enablers as SODIS intervention was a new approach in the study area for the treatment of drinking water. Because the study covered only a small community in a single rural district, findings may not be generalized in many other settings, despite the transferability of findings to similar communities in other parts of rural Ethiopia. To ensure this, until the saturation points were reached, the study group addressed problems in detail.

\section{CONCLUSION}

We conclude that although the transparent appearance of water is viewed as an indicator of water quality, most participants have good understanding of the meaning of clean water. Nearly all participants have a positive attitude toward SODIS which is accepted culturally. The traditional believes, however, that existing in rural communities hinder the safe exposure of SODIS bottles. This is the first study in rural Ethiopia where parents of children younger than 5 years have been asked about barriers and enabling factors that are likely to affect SODIS implementation at home as a low-cost water treatment intervention in low-income settings. In terms of the concept of clean water, types of HWT, and sources of water contamination, the level of understanding of participants was explored. Supportive values for SODIS use, consistent use of SODIS, family and community participation in SODIS implementation, and willingness to pay for SODIS bottles were identified as the important enabling factors to facilitate SODIS intervention. Barriers such as sociocultural (poor knowledge, hesitation to leave SODIS bottles, less attention of parents, and unplanned social functions), environmental (cloud, shadow, turbidity, leeches, and geographical setting), and behavioral (mishandling of SODIS bottles and treated water) aspects were identified as factors that hindered the sustainable implementation of SODIS in rural communities. Maintaining the enabling factors and mitigating the identified potentially modifiable barriers could be the concerns for a wider application of SODIS intervention. Strengthening an effective involvement of communities at important stages of implementation and establishing a system to underpin the inter-sectoral integration between the water development and the health sectors, including the health extension program, are substantially important for the long-term success of SODIS interventions. Finally, it is suggested to carry out research on health education impact as a policy to promote the scale-up of SODIS technology.

Received May 15, 2018. Accepted for publication November 13, 2019.

Published online December 12, 2019. 
Acknowledgments: We would like to thank the University of Gondar for transportation support; the FGD moderators; R. P. Dr. Raju, who edited the final version of the manuscript; Demeke Dessu, who edited the language; and the study participants for their contribution to make this study complete. The American Society of Tropical Medicine and Hygiene (ASTMH) assisted with publication expenses.

Disclosure: Data will be shared upon request of the corresponding author.

Authors' addresses: Bikes Destaw Bitew, Department of Environmental and Occupational Health and Safety, Institute of Public Health, College of Medicine and Health Sciences, University of Gondar, Gondar, Ethiopia, E-mail: bikesdestaw2004@gmail.com. Yigzaw Kebede Gete, Department of Epidemiology and Biostatistics, Institute of Public Health, College of Medicine and Health Sciences, University of Gondar, Gondar, Ethiopia, E-mail: gkyigzaw@yahoo.com. Gashaw Andargie Biks, Department of Health Service Management and Health Economics, Institute of Public Health, College of Medicine and Health Sciences, University of Gondar, Gondar, Ethiopia, E-mail: gashawab@ gmail.com. Takele Tadesse Adafrie, Department of Epidemiology and Biostatistics, School of Public Health, College of Health Sciences and Medicine Referral Hospital, Wolaita Sodo University, Wolaita, Ethiopia, E-mail: takeletadesse1627@gmail.com.

\section{REFERENCES}

1. UNICEF/World Health Organization, 2015.25 Years Progress on Sanitation and Drinking Water-2015 Update and MDG Assessment. The United Nations Children's Fund (UNICEF) and WHO. Geneva, Switzerland: WHO. Available at: http:// www.who.int/water_sanitation_health/publications/jmp-2015update/en/. Accessed December 30, 2018.

2. World Health Organization/UNICE, 2017. Progress on Drinking Water, Sanitation and Hygiene: 2017 Update and SDG Baselines. Geneva, Switzerland: $\mathrm{WHO}$ and the United Nations Children's Fund (UNICEF). Available at: http://www.wipo.int/ amc/en/mediation/rules. Accessed January 15, 2018.

3. Pandit AB, Kumar JK, 2015. Clean water for developing countries. Annu Rev Chem Biomol Eng 6: 217-246.

4. Dean AJ, Fielding KS, Newton FJ, 2016. Community knowledge about water: who has better knowledge and is this associated with water-related behaviors and support for water-related policies? PloS One 11: e0159063.

5. Reynolds KA, Mena KD, Gerba CP, 2008. Risk of waterborne illness via drinking water in the United States. Reviews of Environmental Contamination and Toxicology. Bethesda, MD: Springer, 117-158.

6. World Health Organization, 2010. Strategies for the Safe Management of Drinking-Water for Human consumption. EXECUTIVE BOARD EB127/6, 127th Session, Provisional agenda item 5.4, April 2010. Geneva, Switzerland: WHO. Available at: apps.who.int/gb/ebwha/pdf_files/WHA64/A64_24-en.pdf. Accessed January 16, 2018.

7. NPC, 2016. Federal Democratic Republic of Ethiopia, The Second Growth and Transformation Plan (GTP-II) (2015/16-2019/20). National Planning Commission (NPC), Addis Ababa, May 2016, Vol. I. Available at: dagethiopia.org/new/images/.../GTP2 English_Translation_Final_June_21_2016.pdf. Accessed January 15, 2018.

8. Ojomo E, Elliott M, Goodyear L, Forson M, Bartram J, 2015. Sustainability and scale-up of household water treatment and safe storage practices: enablers and barriers to effective implementation. Int J Hyg Environ Health 218: 704-713.

9. Sobsey MD, 2002. Managing Water in the Home: Accelerated Health Gains from Improved Water Supply. Geneva, Switzerland: World Health Organization. Available at: www.who.int/iris/ handle/10665/67319. Accessed January 16, 2018.

10. McGuigan KG, Joyce TM, Conroy RM, Gillespie JB, ElmoreMeegan M, 1998. Solar disinfection of drinking water contained in transparent plastic bottles: characterizing the bacterial inactivation process. J Appl Microbiol 84: 1138-1148.

11. Kraemer SM, Mosler H-J, 2010. Persuasion factors influencing the decision to use sustainable household water treatment. Int J Environ Health Res 20: 61-79.
12. Rose A, Roy S, Abraham V, Holmgren G, George K, Balraj V, Abraham S, Muliyil J, Joseph A, Kang G, 2006. Solar disinfection of water for diarrhoeal prevention in southern India. Arch Dis Child 91: 139-141.

13. Orgill J, Shaheed A, Brown J, Jeuland M, 2013. Water quality perceptions and willingness to pay for clean water in peri-urban Cambodian communities. J Water Health 11: 489-506.

14. Dessie A, Alemayehu E, Mekonen S, Legesse W, Kloos H, Ambelu A, 2014. Solar disinfection: an approach for low-cost household water treatment technology in southwestern Ethiopia. J Environ Health Sci Eng 12: 25.

15. Bitew BD, Gete YK, Biks GA, Adafrie TT, 2018. The effect of SODIS water treatment intervention at the household level in reducing diarrheal incidence among children under 5 years of age: a cluster randomized controlled trial in Dabat district, northwest Ethiopia. Trials 19: 412.

16. Bitew BD, Gete YK, Biks GA, Adafrie TT, 2017. Knowledge, attitude, and practice of mothers/caregivers on household water treatment methods in northwest Ethiopia: a community-based cross-sectional study. Am J Trop Med Hyg 97: 914-922.

17. Fantahun M, Kumbi S, Degu G, Kebede Y, Admassu M, Haile W, Haile S, 2001. Dabat rural health project, north west Ethiopia: report of the baseline survey. Ethiop J Health Dev 15: 1-28.

18. Francis MR, Nagarajan G, Sarkar R, Mohan VR, Kang G, Balraj V, 2015. Perception of drinking water safety and factors influencing acceptance and sustainability of a water quality intervention in rural southern India. BMC Public Health 15: 731.

19. World Health Organization, 2011. Guidelines for Drinking-Water Quality, 4th edition. Geneva, Switzerland: WHO. Available at: http://www.who.int/about/licensing/copyright_form/en/index.html. Accessed December 30, 2018.

20. Rojas LFR, Megerle A, 2013. Perception of water quality and health risks in the rural area of Medellín. Am $J$ Rural Dev 1: 106-115.

21. Coetzee H, Nell W, Bezuidenhout C, 2016. An assessment of perceptions, sources and uses of water among six African communities in the north west province of South Africa. Water SA 42: 432-441.

22. Rothstein JD, Leontsini E, Olortegui MP, Yori PP, Surkan PJ, Kosek M, 2015. Determinants of caregivers' use and adoption of household water chlorination: a qualitative study with periurban communities in the Peruvian Amazon. Am J Trop Med Hyg 93: 626-635.

23. Rosa G, Huaylinos ML, Gil A, Lanata C, Clasen T, 2014. Assessing the consistency and microbiological effectiveness of household water treatment practices by urban and rural populations claiming to treat their water at home: a case study in Peru. PLOS One 9: e114997.

24. Christen A, Pacheco GD, Hattendorf J, Arnold BF, Cevallos M, Indergand S, Colford JM, Mäusezahl D, 2011. Factors associated with compliance among users of solar water disinfection in rural Bolivia. BMC Public Health 11: 210.

25. Wolf $\mathrm{J}$ et al., 2014. Systematic review: assessing the impact of drinking water and sanitation on diarrhoeal disease in low-and middle-income settings: systematic review and meta-regression. Trop Med Int Health 19: 928-942.

26. Rainey RC, Harding AK, 2005. Acceptability of solar disinfection of drinking water treatment in Kathmandu Valley, Nepal. Int $J$ Environ Health Res 15: 361-372.

27. Shaheed A, Orgill J, Ratana C, Montgomery MA, Jeuland MA, Brown J, 2014. Water quality risks of 'improved' water sources: evidence from Cambodia. Trop Med Int Health 19: 186-194.

28. Rufener S, Mäusezahl D, Mosler H-J, Weingartner R, 2010. Quality of drinking-water at source and point-of-consumption-drinking cup as a high potential recontamination risk: a field study in Bolivia. $J$ Health Popul Nutr 28: 34-41.

29. McGuigan KG, Samaiyar P, du Preez M, Conroy RM, 2011. High compliance randomized controlled field trial of solar disinfection of drinking water and its impact on childhood diarrhea in rural Cambodia. Environ Sci Tech 45: 7862-7867.

30. Halperin M, Paz-SoldÁn VA, Quispe V, Paxton A, Gilman RH, 2011. Sustainability of solar disinfection to provide safe drinking water in rural Peru. Public Health Rep 126: 762-768.

31. Luzi S, Gurung P, Meierhofer R, Wegelin M, 2009. User acceptance: the key to evaluating SODIS and other methods for 
household water treatment and safe storage. Water, Sanitation and Hygiene: Sustainable Development and Multisectoral Approaches. Proceedings of the 34th WEDC International Conference, United Nations Conference Centre, May 18-22, 2009, Addis Ababa, Ethiopia: Water, Engineering and Development Centre (WEDC). Leicestershire, England: University of Technology, 429-433.

32. Meierhofer R, Landolt G, 2009. Factors supporting the sustained use of solar water disinfection-experiences from a global promotion and dissemination programme. Desalination 248: 144-151.

33. Firth J, Balraj V, Muliyil J, Roy S, Rani LM, Chandresekhar R, Kang $G, 2010$. Point-of-use interventions to decrease contamination of drinking water: a randomized, controlled pilot study on efficacy, effectiveness, and acceptability of closed containers, Moringa oleifera, and in-home chlorination in rural south India. Am J Trop Med Hyg 82: 759-765.
34. Cervantes DXF, 2003. Feasibility of Semi-Continuous Solar Disinfection System for Developing Countries at a Household Level. Cambridge, MA: Massachusetts Institute of Technology.

35. Islam MA, Azad AK, Akber MA, Rahman M, Sadhu I, 2015. Effectiveness of solar disinfection (SODIS) in rural coastal Bangladesh. J Water Health 13: 1113-1122.

36. Borde P, Elmusharaf K, McGuigan KG, Keogh MB, 2016. Community challenges when using large plastic bottles for solar energy disinfection of water (SODIS). BMC Public Health 16: 931.

37. Williams HA, Gaines J, Patrick M, Berendes D, Fitter D, Handzel T, 2015. Perceptions of health communication, water treatment and sanitation in Artibonite Department, Haiti, March-April 2012. PLoS One 10: e0142778.

38. Alemu F, Kumie A, Medhin G, Gebre T, Godfrey P, 2017. A socioecological analysis of barriers to the adoption, sustainablity and consistent use of sanitation facilities in rural Ethiopia. BMC Public Health 17: 706. 